\title{
Composite structures defect imaging
}

\section{P. Fromme}

P. Fromme, "Composite structures defect imaging," Proc. SPIE 10600, Health Monitoring of Structural and Biological Systems XII, 106000C (27 March 2018); doi: 10.1117/12.2294522

Event: SPIE Smart Structures and Materials + Nondestructive Evaluation and Health Monitoring, 2018, Denver, Colorado, United States 


\title{
Composite Structures Defect Imaging
}

\author{
P. Fromme \\ Department of Mechanical Engineering, University College London, UK
}

\begin{abstract}
Carbon fiber laminate composites provide good strength to weight ratio for aerospace applications. Manufacturing imperfections and impact during the operation and servicing of the aircraft can lead to barely visible and difficult to detect damage. Impact can lead to delaminations and matrix or fiber cracks, reducing the load carrying capacity of the structure. Both ultrasonic and X-ray techniques have a good track record for the nondestructive testing of composite structures. Immersion ultrasonic C-scans were performed to measure the delamination extent for impact damage in a cross-ply composite specimen. Guided ultrasonic waves propagating along composite plates were employed for defect imaging. The first antisymmetric $\mathrm{A}_{0}$ Lamb wave mode was excited experimentally using piezoelectric transducers and measured using a laser vibrometer. X-ray imaging was used for the detailed visualization of the damages in the composite material. Application examples include carbon fiber composite plates with barely visible impact damage and manufacturing defects. The composite specimens and damage were characterized using ultrasonic measurements. Guided ultrasonic wave and X-ray imaging were used and the respective sensitivity for damage detection in composite panels is discussed.
\end{abstract}

Keywords: Ultrasonics, Lamb Waves, Delamination, Composites, X-ray

\section{INTRODUCTION}

Composite structures offer beneficial strength to weight capacity for the aerospace industry. However, as impacts can result in barely visible damage [1], testing is required. The structural integrity and load bearing capacity can be limited by hidden damage modes such as matrix cracks, fiber damage, and delaminations [2]. Different non-destructive testing methods have been investigated and proposed for the monitoring of composite structures [3,4]. For the detection of manufacturing defects in composite structures such as porosity, in-plane fiber orientation, and out-of-plane ply wrinkling, good sensitivity of ultrasound has been found [5]. The size and location of delaminations (and other defects) can be measured accurately using ultrasonic immersion C-scans [6-8]. Efficient monitoring of large structures can be achieved using guided waves [9]. Damage such as fatigue cracks in metallic and multi-layered structures have been successfully detected using guided waves [10-14]. For anisotropic materials, the propagation of guided waves is dependent on the direction, requiring good understanding for experimental design and analysis [15, 16]. This is especially valid for higher guided wave modes, as in addition to complicated propagation patterns, their attenuation in composite materials is quite high, limiting their potential for defect detection. Often one of the fundamental guided wave modes at low frequencies (below cut-off frequencies of higher wave modes) has been found advantageous for testing. Guided waves have been successfully employed to detect delaminations in composite structures [17, 18]. Experimentally, the scattering of the fundamental $\mathrm{A}_{0}$ guided wave mode at impact damage was measured and compared to Finite Element predictions [19].

X-ray methodologies have demonstrated sensitivity for the detection of internal defects. Due to the limited contrast of Xrays for carbon fiber composites, dye penetrant has often been used [20]. From micro CT scans, damage in composites such as micro cracks and voids can be visualized in 3D and characterized [21]. From X-ray CT scans and ultrasonic Cscans, detailed models in 3D can be developed of composite damage [22]. X-ray phase-contrast imaging (XPCI) methodologies have been proposed for low-contrast applications [23], as discussed in reviews detailing recent developments, methods and applications [24]. These are also referred to as "coded-aperture" and edge-illumination (EI) [25]. For the detection of microscopic inhomogeneities methods such as "dark-field" approaches [26] are well suited.

Health Monitoring of Structural and Biological Systems XII, edited by Tribikram Kundu, Proc. of SPIE Vol. 10600, 106000C · C 2018 SPIE · CCC code: 0277-786X/18/\$18 · doi: 10.1117/12.2294522 


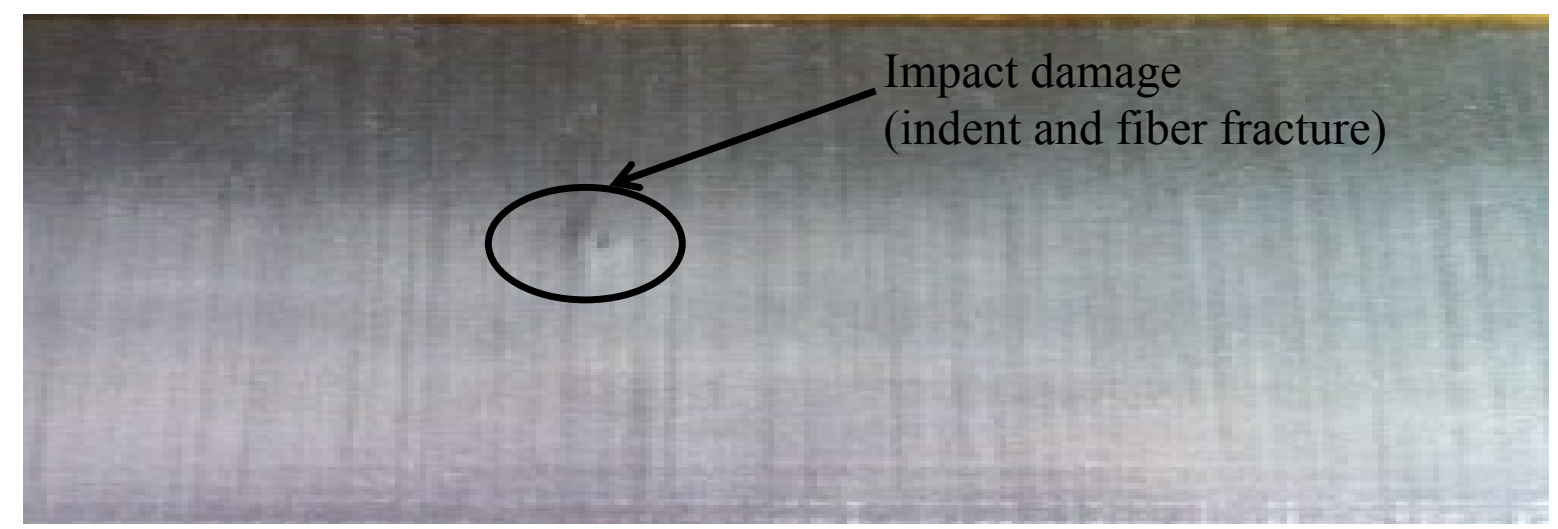

Figure 1: Composite specimen with barely visible impact damage (indent and fiber fracture) marked.

For the visualization of barely visible impact damage in a cross-ply composite plate specimen, complimentary imaging using EI differential phase and dark-field methods, ultrasonic C-scans, and guided waves, were employed [27, 28]. This contribution describes the composite specimen, ultrasonic methods, and the phase-based X-ray imaging system. Experimental results from the different methods are compared and discussed in respect to their complimentary scale and sensitivity.

\section{EXPERIMENTS}

Two cross-ply composite specimens had been manufactured and previously studied by the Composite Systems Innovation Centre at the University of Sheffield, UK [1]. The specimens (990 $\mathrm{mm}$ x $110 \mathrm{~mm}$ ) were manufactured using unidirectional pre-pregs (Cytec 977-2/ Tenax HTS) and autoclave curing. The specimens consist of 8 pre-preg layers with a symmetric, cross-ply layup sequence of $[0 / 90]_{2 \mathrm{~s}}$, resulting in an overall specimen thickness of $2 \mathrm{~mm}$. Using standard drop weight impact procedures, impact damage in one of the specimens had been generated using a standard drop weight impact (7.4 J energy, hemispherical $15 \mathrm{~mm}$ impactor head). Some limited indentation and fiber fracture on the impacted plate was observed (Fig. 1).

Ultrasonic C-scans were performed of the impacted area of the composite plate. A $200 \mathrm{~mm}$ long section was cut out of the specimen. For immersion scanning using a scanning rig, the specimen section was placed in a water bath, with a 12 $\mathrm{mm}$ thick steel plate placed $5 \mathrm{~mm}$ below the composite specimen to perform a double-through transmission ultrasonic Cscan. An additional C-scan was performed, with the time gate set to capture the amplitude peak corresponding to the ultrasonic pulse reflected within the specimen. The scanned area shown was $70 \mathrm{~mm}$ x $35 \mathrm{~mm}$, with a step size of $1 \mathrm{~mm}$ in both lateral directions. For the ultrasonic immersion measurements, an unfocused, quarter inch diameter, $10 \mathrm{MHz}$ center frequency transducer was employed. The signals were recorded using a digital oscilloscope and transferred to a PC for evaluation using MATLAB.

The guided wave field was measured, covering a scan area of $40 \mathrm{~mm}$ x $40 \mathrm{~mm}$ (step size of $1 \mathrm{~mm}$ in both directions) around the impact damage location. The scattered wave field was measured using a laser interferometer attached to a scanning rig and moved parallel to the composite specimen. The fundamental $\mathrm{A}_{0}$ guided wave mode was excited using a custom-built transducer, consisting of a piezoelectric disc (diameter: $5 \mathrm{~mm}$, thickness: $2 \mathrm{~mm}$, polarized in thickness direction) and a bonded brass backing mass (diameter: $5 \mathrm{~mm}$, thickness: $6 \mathrm{~mm}$ ), located $50 \mathrm{~mm}$ from the impact damage center and permanently bonded using a two-component epoxy glue. The excitation signal (5-cycle Hanning windowed tone-burst, center frequency $100 \mathrm{kHz}$ ) was generated using a programmable function generator and amplified to about $200 \mathrm{~V}_{\mathrm{pp}}$. The time traces of the laser signal (proportional to out-of-plane velocity) were band-pass filtered $(75-125 \mathrm{kHz})$ and recorded (20 averages). For the analysis using Matlab software, for each scan point, the maximum amplitude of the time trace was calculated using the Hilbert transform.

Experimental measurements of the specimens using an EI phase-based x-ray imaging system were performed as described in more detail in references [27, 29]. The evaluation of the X-ray imaging allows the calculation of images characterizing the dark-field related to changes in the specimen properties [29]. 
(a)

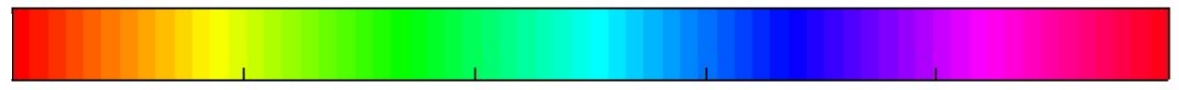
0
0.1
0.2
0.3
0.4
0.5

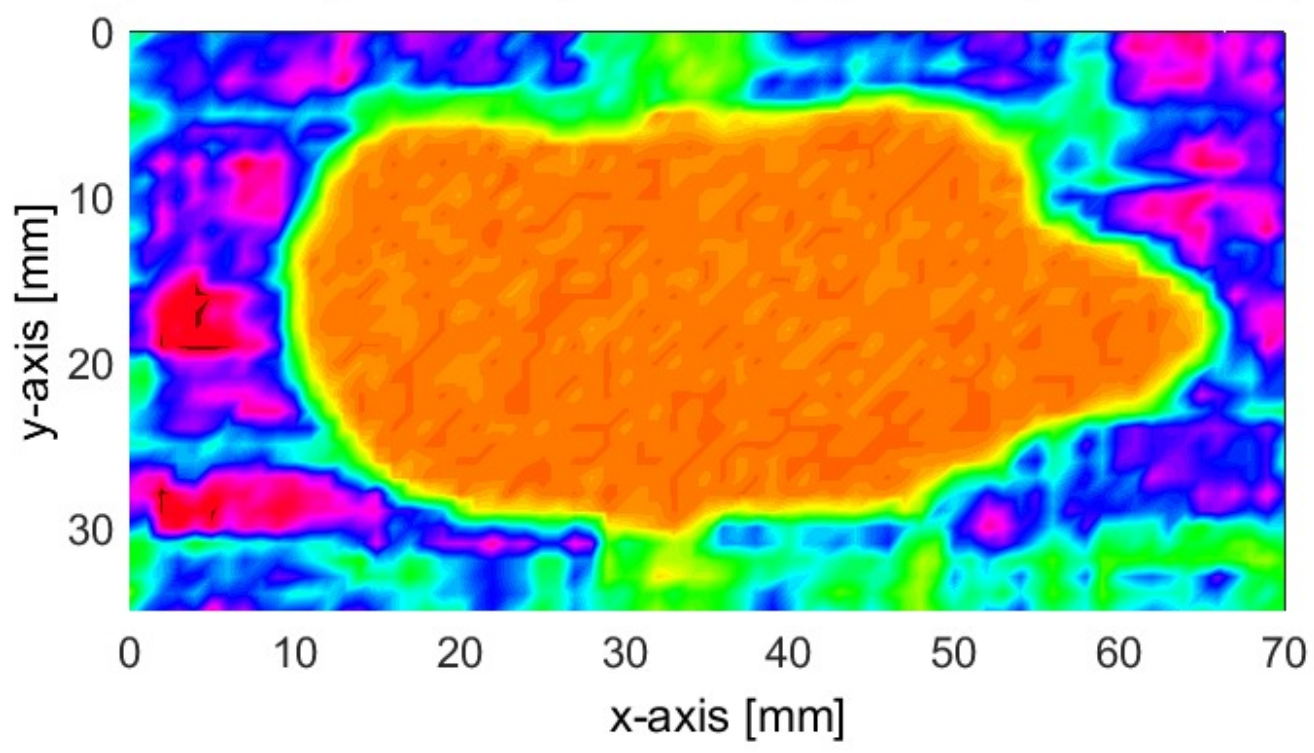

(b)
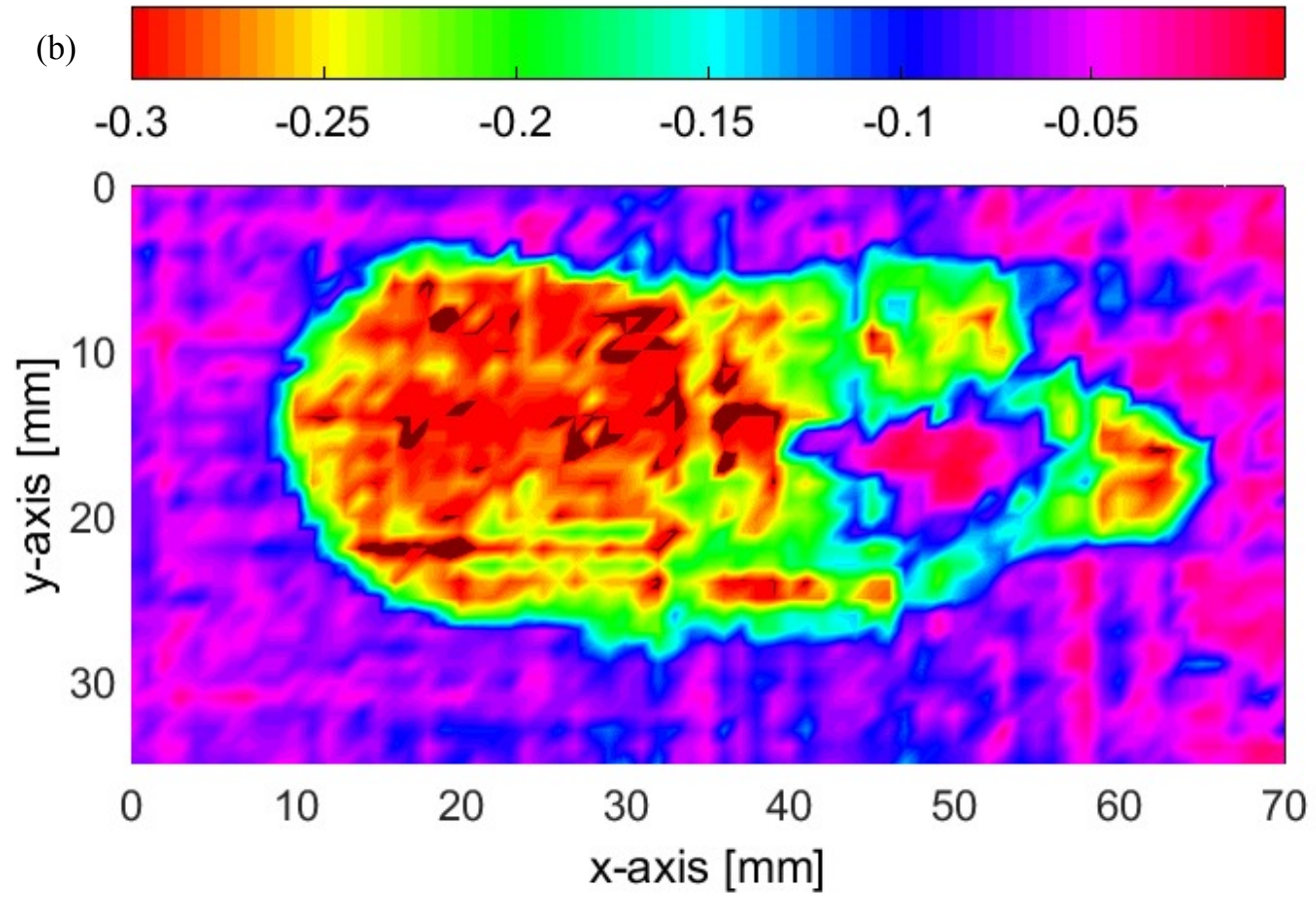

Figure 2: Color-coded ultrasonic immersion C-scan images of damaged composite specimen (scan area: $70 \mathrm{~mm} \times 35$ $\mathrm{mm}$, step size: $1 \mathrm{~mm}$ ); maximum amplitude of ultrasonic signal, $10 \mathrm{MHz}$ immersion transducer: (a) doublethrough transmission; (b) pulse reflection. 


\section{ULTRASONIC IMMERSION C-SCAN}

Figure 2 shows the images obtained from the double-through transmission (Fig. 2a) and pulse reflection (Fig. 2b) immersion C-scans of the damaged area. The center of the impact was located approximately at $\mathrm{x}=50 \mathrm{~mm}, \mathrm{y}=20 \mathrm{~mm}$. The resulting image for the double-through transmission (Fig. 2a) shows the delamination area (extent about $60 \mathrm{~mm}$ in xdirection, $25 \mathrm{~mm}$ in y-direction) with consistent low amplitude (orange) due the interruption of the wave propagation. Within the area of higher amplitude (blue-purple) around the delamination, a pattern due to variations in the ultrasonic transmission and reflection linked to the internal structure and surface of the specimen can be discerned. Furthermore, vertical and horizontal lines of lower amplitude (yellow-green) at distinct locations can be seen, which might indicate damage extending along the fiber orientations for the cross-ply composite plate.

The image showing the amplitude of the reflection C-scan is shown in Fig. 2b. The delamination area can be seen as the increased reflected signal (red-blue, negative amplitude), matching quite well the area found from the double-through transmission C-scan (Fig. 2a). The small, visible surface impact damage (Fig. 1) corresponds to the lower amplitude (around $\mathrm{x}=55 \mathrm{~mm}, \mathrm{y}=25 \mathrm{~mm}$ ), which is not at the center of the delamination area. Similar to the double-through transmission image, some pattern in the area around the delamination can be observed (pink), which corresponds to variations of the composite structure. The wavelength corresponding to the transducer frequency $(10 \mathrm{MHz})$ was not small enough to allow resolution of the individual ply layers.

\section{GUIDED WAVE IMAGING}

Figure 3 shows the amplitude of the guided wave field, scattered at the impact damage, with the incident wave propagating from left to right (y-direction). The scattered field shows an irregular area and pattern of high amplitudes, coinciding with the visible, small indent and center of the delamination. The area of higher amplitudes corresponds reasonably well with the delamination area observed from the ultrasonic immersion C-scans (Fig. 2, rotated by 90 degrees). A significant drop of the amplitude of the guided wave field behind the impact damage $(\mathrm{y}=30-40 \mathrm{~mm})$ compared to the incident amplitude $(\mathrm{y}=0-10 \mathrm{~mm})$ can be observed. This can be correlated to the scattering of the incident guided wave at the impact damage, with limited transmission beyond the defect. As the two ultrasonic methods employ significantly different wave propagation and frequencies, the interaction with the impact damage and thus sensitivity for specific damage mechanisms is different.

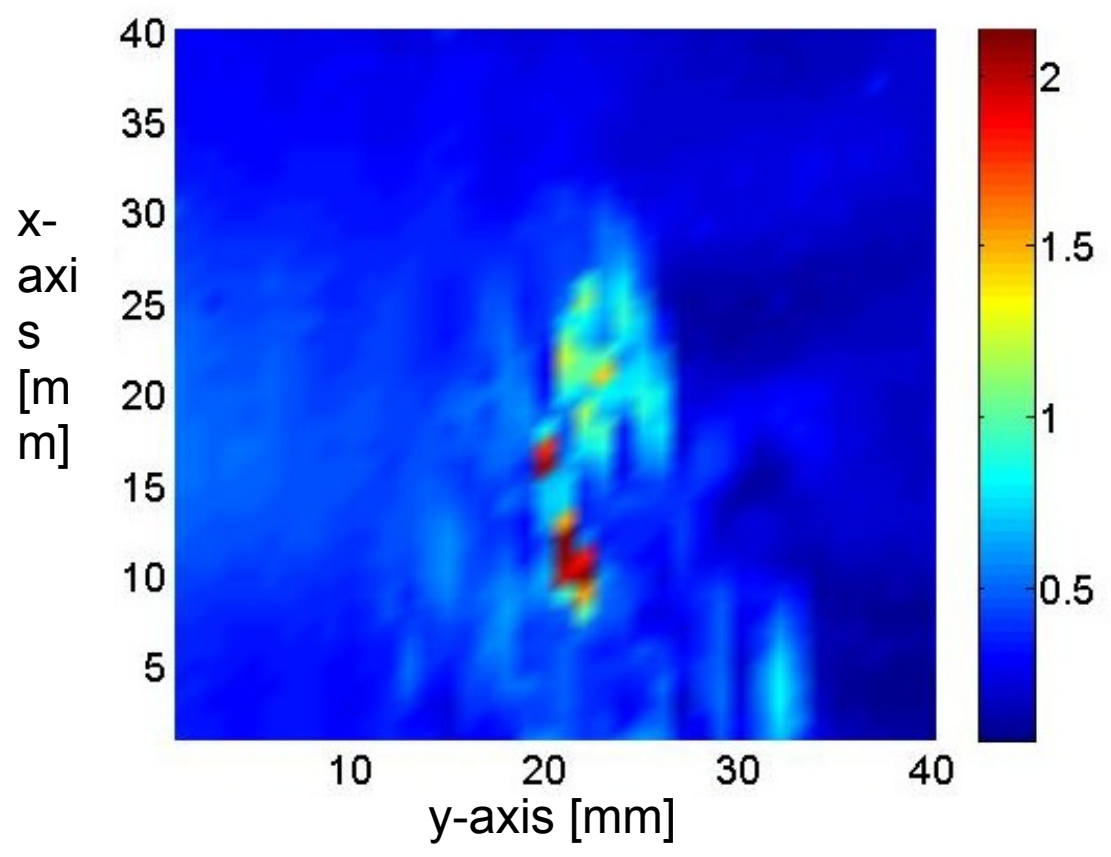

Figure 3: Guided wave amplitude, area around impact damage; fundamental $\mathrm{A}_{0}$ mode, $100 \mathrm{kHz}$ excitation center frequency; $1 \mathrm{~mm}$ step size in both directions; maximum amplitude of time trace. 
(a)

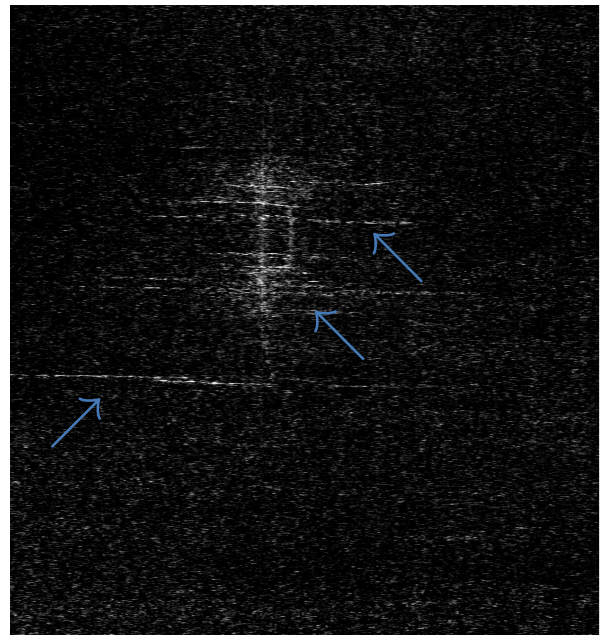

(b)

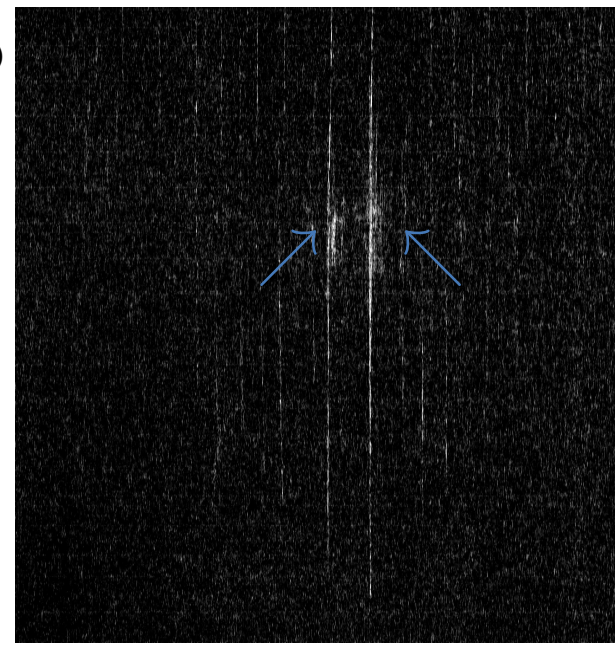

Figure 4: Dark-field X-ray images of composite damage: (a) horizontal; (b) vertical orientation of specimen.

\section{X-RAY EDGE ILLUMINATION PHASE-BASED IMAGING}

The dark-field EI phase contrast images of the damage location are shown in Fig. 4. No dye penetrant was used for the $\mathrm{X}$-ray imaging. The two images were obtained for rotation of the composite specimen by $90^{\circ}$. The phase contrast imaging is sensitive to the damage orientation relative to the mask. In both images, impact damage can be seen, and is highlighted by the arrows. As the X-ray imaging methodology is sensitive to the orientation, the two images show the extent of damage along the two fiber directions of the cross-ply composite specimen.

\section{CONCLUSIONS}

A cross-ply composite specimen containing barely visible impact damage was experimentally tested using complementary non-destructive methods to obtain information about the extent and severity of the impact damage. Impact damage leads to a range of defects in composite structures, ranging in size from delaminations to matrix and fiber cracking. Three imaging methods were compared, using guided waves, ultrasonic immersion C-scans, and phase-based $\mathrm{X}$-ray imaging. Both ultrasonic immersion $\mathrm{C}$-scans provided clear information about the size and shape of the delamination, with additional damage visible. The guided wave measurements at significantly lower excitation frequency and thus larger wavelength showed significant scattering and increased amplitudes in the damage area, allowing the localization of the impact damage, but providing limited information about the exact damage shape. The dark-field EI Xray imaging has orientation-dependent sensitivity for damage aligned with the aperture, typically on a smaller length scale than the ultrasonic immersion C-scans, which could be exploited for more detailed characterization of the impact damage. The different non-destructive imaging methods provided characterization of the impact damage across different length scales. Improved image registration and characterization of impact damages of varying severity could help to improve the sensitivity of the methods and allow improved characterization of the defects.

\section{ACKNOWLEDGMENTS}

The author would like to thank the Composite Systems Innovation Centre, University of Sheffield, UK for the provision of the composite plate, Bibi Intan Suraya Murat for her contribution to the ultrasonic measurements, Marco Endrizzi and Alessandro Olivo for the X-ray measurements.

\section{REFERENCES}

[1] Swait, T. J., Jones, F. R. and Hayes, S. A., "A practical structural health monitoring system for carbon fibre reinforced composite based on electrical resistance," Compos. Sci. Technol. 72, 1515-1523 (2012).

[2] Richardson, M.O.W. and Wisheart, M.J., "Review of low impact velocity properties of composite materials," Compos. A. 27, 1123-1131 (1996). 
[3] Scott, I.G. and Scala, C.M., "A review of non-destructive testing of composite-materials," NDT Int. 15, 75-86 (1982).

[4] Amenabar, I., Mendikute, A., López-Arraiza, A., Lizaranzu, M. and Aurrekoetxea, J., "Comparison and analysis of non-destructive testing techniques suitable for delamination inspection in wind turbine blades," Compos. Part B: Eng. 42, 1298-1305 (2011).

[5] Smith, R.A., Nelson, L.J., Xie, N., Fraij, C. and Hallett, S.R., "Progress in 3D characterisation and modelling of monolithic carbon-fibre composites," Insight 57, 131-139 (2015).

[6] Kiefel, D., Stoessel, R. and Grosse, C., "Quantitative impact characterization of aeronautical CFRP materials with non-destructive testing methods," AIP Conf. Proc. 1650, 591-598 (2015).

[7] Lloyd, P.A., "Ultrasonic system for imaging delaminations in composite-materials," Ultrasonics 27, 8-18 (1989).

[8] Symons, D.D., "Characterisation of indentation damage in 0/90 lay-up T300/914 CFRP," Compos. Sci. Technol. 60, 391-401 (2000).

[9] Hall, J. S., Fromme, P. and Michaels, J. E., "Guided wave damage characterization via minimum variance imaging with a distributed array of ultrasonic sensors," J. Nondestruct. Eval. 33, 299-308 (2014).

[10] Masserey, B. and Fromme, P., "In-situ monitoring of fatigue crack growth using high frequency guided waves," NDT\&E Int. 71, 1-7 (2015).

[11] Masserey, B. and Fromme, P., "High-frequency guided waves for defect detection in stiffened plate structures," Insight 51, 667-671 (2009).

[12] Rouge, C. and Fromme, P., "Directivity of guided ultrasonic wave scattering at notches and cracks," J. Phys.: Conf. Ser. 269, 012018 (2011).

[13] Kostson, E. and Fromme, P., "Fatigue crack growth monitoring in multi-layered structures using guided ultrasonic waves," J. Phys.: Conf. Ser. 195, 012003 (2009).

[14] Masserey, B. and Fromme, P., "Analysis of high frequency guided wave scattering at a fastener hole with a view to fatigue crack detection," Ultrasonics 76, 78-86 (2017).

[15] Castaings, M. and Hosten, B., "Guided waves propagating in sandwich structures made of anisotropic, viscoelastic, composite materials," J. Acoust. Soc. Am. 113, 2622-2634 (2003).

[16] Fromme, P., Pizzolato, M., Robyr, J.-L. and Masserey, B., "Lamb wave propagation in monocrystalline silicon wafers," J. Acoust. Soc. Am. 143, 287-295 (2018).

[17] Toyama, N. and Takatsubo, J., "Lamb wave method for quick inspection of impact-induced delamination in composite laminates," Compos. Sci. Technol. 64, 1293-1300 (2003).

[18] Tan, K.S., Guo, N., Wong, B.S. and Tui, C.G., "Experimental evaluation of delaminations in composite plates by the use of Lamb waves," Compos. Sci. Technol. 53, 77-84 (1995).

[19] Murat, B.I.S., Khalili, P. and Fromme, P., "Scattering of guided waves at delaminations in composite plates," J. Acoust. Soc. Am. 139, 3044-3052 (2016).

[20] Lavoie, J.A. and Adolfsson, E., "Stitch cracks in constraint plies adjacent to a cracked ply," J. Compos. Mater. 35, 2077-2097 (2001).

[21] Schilling, P.J., Karedla, B.P.R., Tatiparthi, A.K., Verges, M.A. and Herrington, P.D., "X-ray computed microtomography of internal damage in fiber reinforced polymer matrix composites," Compos. Sci. Technol. 65, 2071-2078 (2005).

[22] Leckey, C.A.C., Rogge, M.D. and Parker, F.R., "Guided waves in anisotropic and quasi-isotropic aerospace composites: three-dimensional simulation and experiment," Ultrasonics 54, 385-394 (2014).

[23] Fitzgerald, R., "Phase-sensitive X-ray imaging," Phys. Today 53, 23-26 (2000).

[24] Olivo, A. and Castelli, E., "X-ray phase contrast imaging: From synchrotrons to conventional sources," Riv. Nuovo Cimento 37, 467-508 (2014).

[25] Olivo, A. and Speller, R., “A coded-aperture technique allowing X-ray phase contrast imaging with conventional sources,” Appl. Phys. Lett. 91, 074106 (2007).

[26] Endrizzi, M., Diemoz, P.C., Millard, T.P., Jones, J.L., Speller, R.D., Robinson, I.K. and Olivo, A., "Hard X-ray dark-field imaging with incoherent sample illumination," Appl. Phys. Lett. 104, 024106 (2014)

[27] Endrizzi, M., Murat, B.I.S., Fromme, P. and Olivo, A., "Edge-illumination X-ray dark-field imaging for visualising defects in composite structures," Compos. Struct. 134, 895-899 (2015).

[28] Fromme, P., Endrizzi, M. and Olivo, A., "Defect imaging in composite structures," Submitted AIP Conf. Proc. (2018).

[29] Endrizzi, M. and Olivo, A., “Absorption, refraction and scattering retrieval with an edge-illumination-based imaging setup,” J. Phys. D: Appl. Phys. 47, 505102 (2014). 